are likely to require respiratory support in the neonatal period. Despite the complex nature of their congenital heart disease, their surgical outcomes are good in our cohort of babies. The following information can be used when counselling parents antenatally and managing their expectations.

\section{G24(P) ANXIETY AND CHEST PAIN: A CHICKEN AND EGG SITUATION?}

L Doherty. Paediatric department, Torbay Hospital, Torbay and South Devon NHS FT, Torquay, UK

\subsection{6/archdischild-2020-rcpch.13}

Introduction Chest pain is a common paediatric presentation and can cause anxiety in patients, parents and healthcare professionals. Media coverage can heighten anxiety, but underlying cardiac pathology is rare in children. It is important to rule out serious underlying pathology and reassure appropriately.

Case History A 16 year old boy with Type 1 Diabetes Mellitus was referred by his diabetes nurse non-specifically unwell with hyperglycaemia and pallor. He had a two day history of anxiety associated with improving dyspnoea and chest pain, and was taking his GCSEs. He was fully immunised but had been given a recent telephone diagnosis of measles, and is needle phobic.

On presentation, he was tachycardic with otherwise normal observations, and felt to be anxious. He became febrile and tachypnoeic with capillary blood gases showed a worsening non-ketotic metabolic acidosis, and a CRP of 80 . He eventually agreed to a cannula under midazolam sedation 10 hours post attendance.

He developed worsening central chest pain and dyspnoea which prevented him lying flat. An ECG and CXR were requested, however there was no ECG machine on the ward. Furthermore, nursing staff are not trained to record ECGs. On examination, he was pale, sweaty with a soft systolic murmur. His venous bloods showed a haemoglobin of $70, \mathrm{MCV}$ 49 and platelets of 673 .

The ECG showed inferior ST elevation and inferolateral $\mathrm{T}$ wave inversion. A troponin was 1595 and an echocardiogram showed an akinetic inferior wall, dilated right heart, bright pericardium and no pericardial fluid. He was transferred to a tertiary adult cardiac centre, but due to the challenges with his diabetes and needle phobia, was moved to PICU under the paediatric cardiologists. A diagnosis of viral myocarditis was made causing left coronary inflammation, possibly exacerbated by microvascular disease secondary to diabetes, and anaemia.

Conclusion Always rule out serious pathology with a background of chest pain first, and be aware that anxiety may be a cause but also an effect of chest pain. Be aware of becoming task focused, and the risk of not seeing the bigger picture.

\section{G25(P) DRUG INDUCED SHORT QT INTERVAL WITH USE OF ANTI-EPILEPTIC MEDICATIONS}

S Choopa, R Sesham, P Nair. Paediatric Department, Bedford Hospital NHS Trust, Bedford, UK

10.1136/archdischild-2020-rcpch.14
Introduction Although drug induced long QT intervals is known to have proarrhythmogenic effect, the same is not known about drug induced short QT intervals. Drug induced short QT syndrome is a rare occurrence and have mainly been reported with the use of anti epileptic medications. Proarrhythmic effects of drug induced QT shortening has only been shown with digitalis. The clinical relevance of drug induced QT shortening is currently unclear.

Case Report We report a case of drug induced QT shortening in a 15 year old boy being treated for Juvenile Myoclonic epilepsy. He was initially being treated with Sodium Valproate with later addition of levetiracetam. He started having complaints of intermittent palpitations and occasional dizziness. He was otherwise well with no family history of sudden deaths etc. His examination and echocardiography were normal. His ECG showed sinus rhythm with a QT interval of 340 milliseconds. His previous ECG 6 months ago had shown a QT interval of 330 milliseconds. An ECG done 3 years ago at diagnosis had shown a normal QT interval of $400 \mathrm{~ms}$. He had subsequent multiple ambulatory monitoring and exercise stress tests which were also normal. He is under ongoing follow up with the cardiac team and his anti-epileptic medications have been continued.

Discussion Drug induced short QT interval is a rare phenomenon and have been mainly seen with use of some antiepileptics, digitalis \& promethazine. Although there have been case reports of QT prolongation with use of levetiracetam, we could not find any reports of QT shortening. There were few reports of QT shortening when sodium valproate was used as a co-medication. In this case we are not sure if it is the valproate on its own or the addition of levetiracetam which caused the QT shortening. However based on no evidence of proarrhythmogenic effect with drug induced QT shortening, we agreed to continue his anti epileptic medications while closely monitoring him. More evidence base and research is needed to throw light on management of patients with drug induced short QTintervals.

\section{G26(P) SCREENING FOR CONGENITAL HEART DISEASE AMONG PRIMARY SCHOOL CHILDREN IN KHARTOUM STATE}

${ }^{1} \mathrm{E}$ Babikir, ${ }^{2} \mathrm{~B}$ Elbasheer, ${ }^{3} \mathrm{R}$ Berair. 'MBBS, MD Paediatrics SMSB, Fedail Hospital, Khartoum, Sudan; ${ }^{2}$ MBBS, MD Paediatrics U of K, PCIC Malaysia, El-Mawadah Hospital, Khartoum, Sudan; ${ }^{3}$ MBBS, MD paediatrics CES, El-Akademi Hospital, Khartoum, Sudan

\subsection{6/archdischild-2020-rcpch.15}

Background Congenital heart defects are the most common type of birth defects and remain the leading cause of death from congenital malformations.

Aims To determine the prevalence of latent congenital heart disease (CHD) among Governmental primary school children in Khartoum state.

Methods This is Descriptive cross sectional school based study which was conducted in the three localities in Khartoum state (the capital of Sudan) which are Sharq Alneel, Khartoum and Omdurman locality using a multistage clustered sampling technique recruited 2400 pupils aged between 6 and 14. Team of doctors worked the history and clinical examination to be related to Echocardiography (Echo) findings which had been done by consultant 